International Journal of

Molecular Sciences

ISSN 1422-0067

www.mdpi.com/journal/ijms

Article

\title{
An Efficient Total Synthesis of a Potent Anti-Inflammatory Agent, Benzocamphorin F, and Its Anti-Inflammatory Activity
}

\author{
Yu-Ren Liao ${ }^{1, \dagger}$, Ping-Chung Kuo ${ }^{2}$, Jun-Weil Liang ${ }^{1}$, Yuh-Chiang Shen ${ }^{3, \dagger}$ \\ and Tian-Shung $\mathrm{Wu} \mathbf{u}^{1,4,5}, *$
}

1 Department of Chemistry, National Cheng Kung University, Tainan 701, Taiwan;

E-Mails: 13892101@mail.ncku.edu.tw (Y.-R.L.); 136994279@mail.ncku.edu.tw (J.-W.L.)

2 Department of Biotechnology, National Formosa University, Yunlin 632, Taiwan;

E-Mail: pcckuoo@sunws.nfu.edu.tw

3 National Research Institute of Chinese Medicine, Taipei 112, Taiwan;

E-Mail: yuhcs@nricm.edu.tw

4 Department of Pharmacy, China Medical University, Taichung 401, Taiwan

5 Chinese Medicinal Research and Development Center, China Medical University Hospital, Taichung 401, Taiwan

$\dagger$ These authors contributed equally to this work.

* Author to whom correspondence should be addressed; E-Mail: tswu@mail.ncku.edu.tw;

Tel.: +886-6-2757575 (ext. 65333); Fax: +886-6-2740552.

Received: 26 June 2012; in revised form: 10 August 2012 / Accepted: 16 August 2012 /

Published: 21 August 2012

\begin{abstract}
A naturally occurring enynyl-benzenoid, benzocamphorin F (1), from the edible fungus Taiwanofungus camphoratus (Antrodia camphorata) was characterized by comprehensive spectral analysis. It displays anti-inflammatory bioactivity and is valuable for further biological studies. The present study is the first total synthesis of benzocamphorin $\mathrm{F}$ and the developed strategy described is a more efficient procedure that allowe the large-scale production of benzocamphorin $F$ for further research of the biological activity both in vitro and in vivo.
\end{abstract}

Keywords: Antrodia camphorata; benzocamphorin F; anti-inflammatory 


\section{Introduction}

Inflammation is related to morbidity and mortality of many diseases and is recognized as part of the complex biological response of vascular tissues to harmful stimuli. It is the host response to infection or injury, which involves the recruitment of leukocytes and the release of inflammatory mediators, including nitric oxide (NO). NO is the metabolic by-product of the conversion of L-arginine to L-citrulline by a class of enzymes termed NO synthases (NOS). Numerous cytokines can induce the transcription of inducible NO synthase ( $i \mathrm{NOS})$ in leukocytes, fibroblasts, and other cell types, accounting for enhanced levels of NO. Although NO is a microbicide and may have important roles in tissue adapting to inflammatory states, overproduction of NO may exacerbate tissue injury in both acute and chronic inflammatory conditions. In the experimental model of acute inflammation, inhibition of $i$ NOS can have a dose-dependent protective effect, suggesting that NO promotes edema and vascular permeability. NO also has a detrimental effect in chronic models of arthritis, whereas protection is seen with $i$ NOS inhibitors [1,2]. For example, glucocorticoids, which are often used in the treatment of inflammation, are able to inhibit the expression of $i$ NOS. Therefore, the extracts of Taiwanofungus camphoratus, which are considered as a rich source of triterepnoids, were examined for their anti-inflammatory activity to explore the new lead drugs. T. camphoratus (synonyms: Ganoderma camphoratum; Antrodia cinnamomea; Antrodia camphorata) (Polyporaceae, Aphyllophorales) is a rare and precious medical fungus in Taiwan and is called a "national treasure of Taiwan" with the Chinese name of Zhan-Ku or Niu-Chang-Chih [3]. The microorganism is parasitic to the inner heartwood wall of old hollow trunks of Cinnamomum kanehirai Hay. (Lauraceae). In traditional Taiwanese folk medicine T. camphoratus has been used as an important health food for treating food, alcohol, and drug intoxication, diarrhea, abdominal pain, hypertension, itching, and liver cancer $[4,5]$. Previous studies have revealed that Niu-Chang-Chih exerts various biological activities, such as hepatoprotective, antihepatitis B virus, anticancer, antioxidant, and anti-inflammatory activities [6,7]. The chemical constituents of this fungus can be divided into the three classes of polysaccharides, triterpenoids, and enynyl-benzenoids [8,9]. Our ongoing study on the chemical composition of the ethanol extract of the fruiting body of $T$. camphoratus has led to the isolation of one new enynyl-benzenoid, benzocamphorin F (1) (Figure 1). In the present study, we wish to report the structural determination of benzocamphorin F (1), as well as an evaluation of its anti-inflammatory activity. In addition, we developed a more efficient synthetic protocol that allowed the large-scale production of benzocamphorin $\mathrm{F}$ for the further research of its biological activity.

Figure 1. Structure of benzocamphorin F (1).

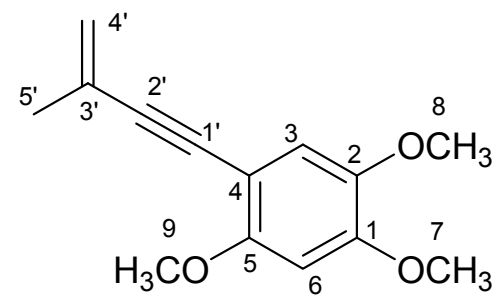




\section{Results and Discussion}

\subsection{Isolation and Structural Elucidation}

The ether-soluble fraction of the crude extract acquired for this study was successively subjected to column chromatography to yield benzocamphorin F (1). The structure of compound $\mathbf{1}$ was elucidated by the methods of UV, IR, HR-ESI/MS, ESI-MS/MS and NMR.

Benzocamphorin F (1) was isolated as colorless powder and showed a $[\mathrm{M}+\mathrm{Na}]^{+}$ion peak at $\mathrm{m} / z$ 255.0997 in its HRESIMS, corresponding to the molecular formula $\mathrm{C}_{14} \mathrm{H}_{16} \mathrm{O}_{3} \mathrm{Na}$. The UV spectrum of 1 displayed absorption maxima at 246, 258, 282 and $317 \mathrm{~nm}$, and the IR spectrum exhibited strong absorption peaks for carbon-carbon triple bond $\left(2183 \mathrm{~cm}^{-1}\right)$, and carbon-carbon double bond $\left(1605 \mathrm{~cm}^{-1}\right)$, respectively. The ${ }^{1} \mathrm{H}$ NMR $\left(\mathrm{CDCl}_{3}\right)$ spectra of $\mathbf{1}$ showed signals assignable to a set of single aromatic protons at $\delta 6.91(1 \mathrm{H}, \mathrm{s}, \mathrm{H}-3), 6.48(1 \mathrm{H}, \mathrm{s}, \mathrm{H}-6)$, terminal methylene protons at $\delta 5.38$ $\left(1 \mathrm{H}, \mathrm{s}, \mathrm{H}-4^{\prime}\right)$ and $\delta 5.26\left(1 \mathrm{H}, \mathrm{s}, \mathrm{H}-4{ }^{\prime}\right)$, three methoxy singlets at $\delta 3.90(3 \mathrm{H}, \mathrm{H}-5), 3.88(3 \mathrm{H}, \mathrm{H}-1)$ and $3.84(3 \mathrm{H}, \mathrm{H}-2)$, and a methyl singlet at $\delta 2.02(3 \mathrm{H}, \mathrm{s}, \mathrm{H}-3 \mathrm{\prime})$, respectively. The ${ }^{13} \mathrm{C}$ NMR and DEPT spectra combined with heteronuclear multiple-quantum correlation (HMQC) experiment indicated 14 signals including an olefinic carbon resonances at $\delta 121.2$, three methoxy groups at $\delta 56.0,56.4$ and 56.9 , two aromatic methines at $\delta 97.4$ and 115.9 , a methyl group at $\delta 23.6$, seven quaternary carbons at $\delta 155.3,150.3,142.9,127.1,103.4,93.5$ and 84.7. The heteronuclear multiple-bond correlations (HMBC) (Figure 2) from $\mathrm{OCH}_{3}-7(\delta 3.88)$ to $\mathrm{C}-1(\delta 155.3)$, from $\mathrm{OCH}_{3}-8(\delta 3.84)$ to $\mathrm{C}-2(\delta 142.9)$, from $\mathrm{H}-3\left(\delta\right.$ 6.91) to $\mathrm{C}-1(\delta 155.3) / \mathrm{C}-2(\delta 142.9) / \mathrm{C}-4(\delta 103.4) / \mathrm{C}-5(\delta 150.3)$, from $\mathrm{OCH}_{3}-9(\delta$ 3.90) to

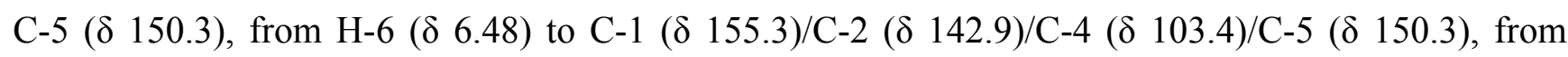
$\mathrm{CH}_{3}-5^{\prime}\left(\delta\right.$ 2.00) to $\mathrm{C}-2^{\prime}\left(\delta\right.$ 93.5)/C-3' $\left(\delta\right.$ 127.0)/C-4' $\left(\delta\right.$ 121.2), from $\mathrm{H}-4{ }^{\prime}(\delta$ 5.38, 5.26) to C-2' $\left(\delta\right.$ 93.5)/C-3' $\left(\delta\right.$ 127.0)/ $/ \mathrm{CH}_{3}-3^{\prime} \quad(\delta$ 23.6) constructed the substituted pattern of this enynyl-benzenoid. On the basis of these spectral data (Table 1), the chemical structure of 1 was identified as shown in Figure 1. It is the first report of this compound from the natural sources and it was given the trivial name, benzocamphorin F, proposed following a previous convention [9].

Table 1. The ${ }^{1} \mathrm{H}$ and ${ }^{13} \mathrm{C}$ NMR chemical shifts of compound $\mathbf{1}$ in $\mathrm{CDCl}_{3}$.

\begin{tabular}{cccc}
\hline Positions & $\boldsymbol{\delta} \mathbf{H}(\mathbf{p p m})$ & $\boldsymbol{\delta} \mathbf{C}(\mathbf{p p m})$ & $\mathbf{H M B C}$ \\
\hline 1 & $/$ & $155.3(\mathrm{C})$ & \\
2 & $/$ & $142.9(\mathrm{C})$ & \\
3 & $6.91(\mathrm{~s}, 1 \mathrm{H})$ & $116.0(\mathrm{CH})$ & $\mathrm{C}-1, \mathrm{C}-2, \mathrm{C}-4, \mathrm{C}-5, \mathrm{C}-1^{\prime}$ \\
4 & $/$ & $103.4(\mathrm{C})$ & \\
5 & $/$ & $150.3(\mathrm{C})$ & $\mathrm{C}-1, \mathrm{C}-2, \mathrm{C}-4, \mathrm{C}-5$ \\
6 & $6.48(\mathrm{~s}, 1 \mathrm{H})$ & $97.4(\mathrm{CH})$ & $\mathrm{C}-1$ \\
7 & $3.88(\mathrm{~s}, 3 \mathrm{H})$ & $56.9\left(\mathrm{CH}_{3}\right)$ & $\mathrm{C}-2$ \\
8 & $3.84(\mathrm{~s}, 3 \mathrm{H})$ & $56.4\left(\mathrm{CH}_{3}\right)$ & \\
9 & $3.90(\mathrm{~s}, 3 \mathrm{H})$ & $56.0\left(\mathrm{CH}_{3}\right)$ & \\
$1^{\prime}$ & $/$ & $93.5(\mathrm{C})$ & $\mathrm{C}-2^{\prime}, \mathrm{C}-3^{\prime}, \mathrm{C}-5^{\prime}$ \\
$2^{\prime}$ & $/$ & $84.7(\mathrm{C})$ & \\
$3^{\prime}$ & $/$ & $127.0(\mathrm{C})$ & $\mathrm{C}-2^{\prime}, \mathrm{C}-3^{\prime}, \mathrm{C}-4^{\prime}$ \\
$4^{\prime}$ & $5.26(\mathrm{~s}, 1 \mathrm{H})$ & $121.2\left(\mathrm{CH}_{2}\right)$ & \\
& $5.38(\mathrm{~s}, 1 \mathrm{H})$ & & \\
$5^{\prime}$ & $2.00(\mathrm{~s}, 3 \mathrm{H})$ & $23.6\left(\mathrm{CH}_{3}\right)$ & \\
\hline
\end{tabular}


Figure 2. Heteronuclear multiple-bond correlation $(\mathrm{HMBC})(\rightarrow)$ correlations for benzocamphorin F (1).

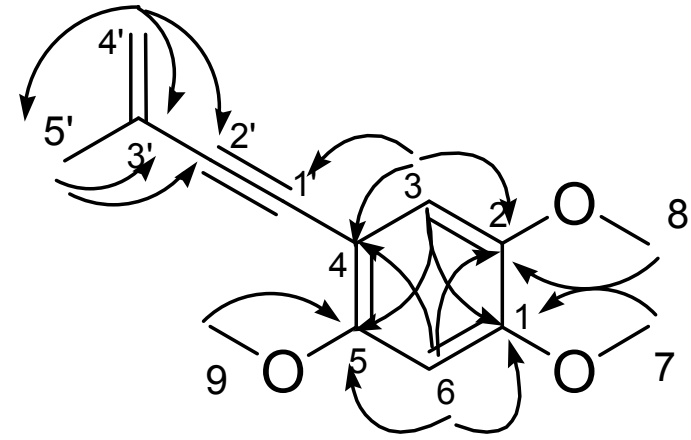

\subsection{Chemistry}

In the previous literature, Wu et al. reported a total synthesis of antrocamphin A with six steps and an overall yield of 3.7\% [10]. However, the low yield and high cost of the reagents for this method reduce the application efficiency. Herein we wish to explore a more efficient and economic method to prepare the analogs possessing the same skeleton as that of antrocamphin A. The retro-synthetic analysis of benzocamphorin F (1) was displayed in Figure 3 and thus we initiated the preparation of 1 from 1,2,4-trimethoxybenzene (3). The $N$-Bromosuccinimide (NBS)-assisted bromination of $\mathbf{3}$ resulted in the 1-bromo-2,4,5-trimethoxybenzene 2 as shown in Figure 4 [11]. Compound 2 was coupled with 2-methyl-3-butyn-2-ol by Sonogashira reaction [12], which successively led to compound 4 . Finally the dehydration of compound $\mathbf{4}$ in toluene by methanesulfonyl chloride to produce benzocamphorin F (1) in good yield (92\%) in Figure 4 [13]. The chemical structure of synthetic compound 1 was elucidated by $1 \mathrm{D}$ and 2D-NMR and mass spectrometry and compared with those of the purified natural compound. The present synthetic protocol of benzocamphorin F (1) provides a more efficient synthetic pathway with a satisfactory overall yield (three steps, 68.9\%). In addition, the reagents used in this synthesis were of comparatively low cost, thus it would be more suitable for the large-scale production of benzocamphorin $\mathrm{F}$ and the analogs with similar skeleton.

Figure 3. Retrosynthetic analysis of benzocamphorin F (1).<smiles>C=C(C)C#Cc1cc(OC)c(OC)cc1OC</smiles>

1

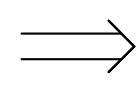<smiles>COc1cc(OC)c(OC)cc1Br</smiles>

2

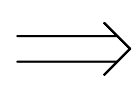<smiles>COc1ccc(OC)c(OC)c1</smiles>

3 
Figure 4. Synthesis of benzocamphorin F (1).<smiles>COc1ccc(OC)c(OC)c1</smiles>

3

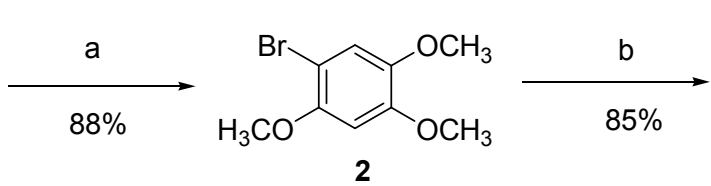

2<smiles>COc1cc(OC)c(OC)cc1C#CC(C)(C)O</smiles><smiles>C=C(C)C#Cc1cc(OC)c(OC)cc1OC</smiles>

Reagents and conditions: a) NBS, acetonitrile, room temp; b) 2-methyl-3-butyn-2-ol, $\mathrm{Pd}\left(\mathrm{PPh}_{3}\right)_{4}, \mathrm{CuI}$, DMF; c) methanesulfonyl chloride, toluene, microwave.

\subsection{Anti-Inflammatory Activity}

The quantity of purified benzocamphorin F (1) from natural sources was too small to be examined for bioactivity. Thus only the inhibitory effect of synthetic benzocamphorin F (1) on LPS-induced NO production in murine microglial cells (BV2) was investigated. Nitrite accumulated in the culture medium was estimated by the Griess reaction as an index for NO release from the cells [12]. When BV2 were treated with different concentrations of 1 together with LPS $(0.5 \mu \mathrm{g} / \mathrm{mL})$ for $24 \mathrm{~h}$, a significant concentration-dependent inhibition of nitrite production was detected. The $\mathrm{IC}_{50}$ value for inhibition of nitrite production of 1 was $8.6 \pm 2.7 \mu \mathrm{M}$. It was more potent than L-NAME ( $\mathrm{IC}_{50}: 12.0 \pm 0.6 \mu \mathrm{M}$ ), a non-specific NOS inhibitor. To further understand whether 1 also exerted anti-oxidative properties, its effect on NOX activity was examined. Our data suggest that compound $\mathbf{1}\left(\mathrm{IC}_{50}\right.$ : $\left.74.4 \pm 9.5 \mu \mathrm{M}\right)$ was an ordinary inhibitor of NOX, as compared to the specific NOX inhibitor, DPI $\left(\mathrm{IC}_{50}: 0.96 \pm 0.06 \mu \mathrm{M}\right)$ (Table 2), indicating that NOX might not be the direct target. The free radical-scavenging capacity of compound 1 was also examined in a cell-free DPPH solution and it did not show considerable free radical-scavenging activity. Trolox, a vitamin $\mathrm{E}$ analogue included as a positive control, displayed a stronger free radical-scavenging effect than the examined compound (Table 2).

Table 2. Summary of the effects of benzocamphorin F on nitric oxide synthase (NOS), NADPH oxidase (NOX) activity in murine microglial cells and DPPH assay.

\begin{tabular}{cccc}
\hline \multirow{2}{*}{ Compound } & \multicolumn{3}{c}{$\mathbf{I C}_{\mathbf{5 0}}(\mu \mathrm{M})$} \\
\cline { 2 - 4 } & NOS & NOX & DPPH \\
\hline $\mathbf{1}$ & $8.6 \pm 2.7^{*}$ & $74.4 \pm 9.5$ & NA \\
L-NAME & $12.0 \pm 0.6$ & NA & NA \\
DPI & NA & $0.96 \pm 0.06$ & NA \\
Trolox & NA & NA & $21.3 \pm 1.6$ \\
\hline
\end{tabular}

NOX and NOS activity were measured by ROS and NO production, respectively, in the presence of $1-50 \mu \mathrm{M}$ of drugs. DPI (diphenyleneiodonium, a NOX inhibitor) and L-NAME (a NOS inhibitor) were included as positive controls. Data were calculated as $50 \%$ inhibitory concentration $\left(\mathrm{IC}_{50}\right)$ and expressed as means \pm SEM from 5 to 6 experiments performed on different days using cells from different passages. $* p<0.05$ as compared with relative positive control, respectively. 


\section{Experimental Section}

\subsection{General}

Melting points were determined using the Yanagimoto MP-S3 micro melting point apparatus without correction. Optical rotations were measured using a Jasco DIP-370 digital polarimeter. UV spectra were obtained on a Hitachi UV-3210 spectrophotometer, and IR spectra were recorded on a Shimadzu FT-IR DR-8011 spectrophotometer. ${ }^{1} \mathrm{H}$ NMR $(400 \mathrm{MHz})$ and ${ }^{13} \mathrm{C}$ NMR $(75 \mathrm{MHz})$ spectra were recorded on Bruker AMX-400 spectrometers using $\mathrm{CDCl}_{3}$ as the solvents. Chemical shifts are shown in $\delta$ values (ppm) with tetramethylsilane as an internal standard. ESI and HR-ESI mass spectra were measured on a Bruker APEX II mass spectrometer. Microwave irradiation was carried out using the CEM LabMate microwave apparatus. Reversed-phase column chromatography was accomplished with Diaion HP-20 and Sephadex LH-20 columns. Silica gel column chromatography was carried out using Kieselgel 60 (70-230 and 230-400 mesh, Merck). Thin-layer chromatography (TLC) was executed on pre-coated Kieselgel $60 \mathrm{~F}_{254}$ plates (Merck), with compounds visualized by UV light or spraying with $10 \%(v / v) \mathrm{H}_{2} \mathrm{SO}_{4}$ followed by charring at $110{ }^{\circ} \mathrm{C}$ for $10 \mathrm{~min}$.

\subsection{Extraction and Isolation}

The fruiting body of $T$. camphoratus $(1.0 \mathrm{~kg})$ was extracted with $\mathrm{Et}_{2} \mathrm{O}(4 \times 10 \mathrm{~L})$ for three days. The $\mathrm{Et}_{2} \mathrm{O}$ extract was concentrated to afford a brown syrup $(360 \mathrm{~g})$ and then partitioned between $\mathrm{H}_{2} \mathrm{O}$ and $\mathrm{Et}_{2} \mathrm{O}$. The ether layer was chromatographed on silica gel and eluted with $\mathrm{MeOH}$ in chloroform (0-100\% of $\mathrm{MeOH}$, gradient) to obtain eight fractions, (Fr. A-H) monitored by TLC. Fr. C was chromatographed on a column of silica gel, eluted successively with a gradient of petroleum $n$-hexane-EtOAc (3:1 to 1:2) as eluent to yield 1 (18.0 mg). Fr. H was chromatographed on a column of silica gel, eluted successively with a gradient of petroleum $i$ - $\operatorname{Pr}_{2} \mathrm{O}-\mathrm{EtOAc}(15: 1)$ as eluent to yield 2 $(24.0 \mathrm{mg})$.

\subsection{Preparation of the Compound (1)}

Synthesis of 1-bromo-2,3,5-trimethoxybenzene (2). A mixture of $\mathbf{3}$ (2.0 g, $11.9 \mathrm{mmol})$, $N$-Bromosuccinimide $(2.1 \mathrm{~g}, 11.9 \mathrm{mmol})$ in $\mathrm{MeCN}(30 \mathrm{~mL})$ was stirred in an ice bath, and the reaction mixture was checked by TLC. The mixture was diluted with water $(50 \mathrm{~mL})$ and then extracted by EtOAc $(100 \mathrm{~mL} \times 3)$. The combined organic phases were washed with water and brine, and further dried over anhydrous $\mathrm{MgSO}_{4}$. The crude was purified by column chromatography over silica gel using $n$-hexane:EtOAc (30:1) to obtain $2(2.6 \mathrm{~g}, 88 \%)$ as pale yellow powder. 2: ${ }^{1} \mathrm{H} \mathrm{NMR}(400 \mathrm{MHz}$, $\left.\mathrm{CDCl}_{3}\right) \delta: 7.03(1 \mathrm{H}, \mathrm{s}, \mathrm{H}-3), 6.56(1 \mathrm{H}, \mathrm{s}, \mathrm{H}-6), 3.88\left(3 \mathrm{H}, \mathrm{s}, \mathrm{OCH}_{3}-5\right), 3.86\left(3 \mathrm{H}, \mathrm{s}, \mathrm{OCH}_{3}-1\right), 3.83(3 \mathrm{H}, \mathrm{s}$, $\left.\mathrm{OCH}_{3}-2\right) ;{ }^{13} \mathrm{C} \mathrm{NMR}\left(75 \mathrm{MHz}, \mathrm{CDCl}_{3}\right) \delta: 150.3,149.1,143.8,116.4,101.1,98.9,57.2,56.6,56.2$; HR-ESI-MS $m / z 268.9798[\mathrm{M}+\mathrm{Na}]$ (calcd for $\mathrm{C}_{9} \mathrm{H}_{9} \mathrm{BrO}_{3}, 245.9982$ ).

Synthesis of 2-methyl-4-(2,4,5-trimethoxyphenyl)but-3-yn-2-ol (4). A mixture of 2 (0.5 g, $2.0 \mathrm{mmol})$, 2-methyl-3-butyn-2-ol (0.26 g, $3.1 \mathrm{mmol}), \mathrm{Pd}\left(\mathrm{PPh}_{3}\right)_{4}(5 \%$ eq) and $\mathrm{CuI}(10 \%$ eq $)$ in $\mathrm{DMF}$ $(15 \mathrm{~mL})$ was stirred at reflux and the reaction mixture was checked by TLC. The mixture was diluted with water $(50 \mathrm{~mL})$ and then extracted by EtOAc $(100 \mathrm{~mL} \times 3)$. The combined organic phases were 
washed with water and brine, and further dried over anhydrous $\mathrm{MgSO}_{4}$. The crude was purified by column chromatography over silica gel using $n$-hexane:EtOAc $(3: 1)$ to obtain $4(0.43 \mathrm{~g}, 85 \%)$ as pale yellow oil. 4: ${ }^{1} \mathrm{H}$ NMR (400 MHz, $\left.\mathrm{CDCl}_{3}\right) \delta: 6.87(1 \mathrm{H}, \mathrm{s}, \mathrm{H}-3), 6.47(1 \mathrm{H}, \mathrm{s}, \mathrm{H}-6), 3.89(3 \mathrm{H}, \mathrm{s}$, $\left.\left.\mathrm{OCH}_{3}-5\right), 3.85\left(3 \mathrm{H}, \mathrm{s}, \mathrm{OCH}_{3}-1\right), 3.83\left(3 \mathrm{H}, \mathrm{s}, \mathrm{OCH}_{3}-2\right), 1.65\left(6 \mathrm{H}, \mathrm{s}, \mathrm{CH}_{3}-3\right)^{\prime}\right) ;{ }^{13} \mathrm{C} \mathrm{NMR}(75 \mathrm{MHz}$, $\left.\mathrm{CDCl}_{3}\right) \delta: 150.3,149.1,143.8,116.4,101.1,98.9,98.3,80.2,65.8,32.1,57.2$, 56.6, 56.2; HR-ESI-MS $m / z 273.1198[\mathrm{M}+\mathrm{Na}]\left(\right.$ calcd for $\left.\mathrm{C}_{14} \mathrm{H}_{18} \mathrm{O}_{4}, 250.1205\right)$.

Synthesis of benzocamphorin F (1). A mixture of $4(0.5 \mathrm{~g}, 2.0 \mathrm{mmol})$ and methanesulfonyl chloride $(0.35 \mathrm{~g}, 3 \mathrm{mmol})$ in toluene $(10 \mathrm{~mL})$ was stirred by microwave $\mathrm{r}$ at $100{ }^{\circ} \mathrm{C}, 100 \mathrm{~W}$ for $8 \mathrm{~min}$ ( 2 min ramp time followed by $6 \mathrm{~min}$ at $100{ }^{\circ} \mathrm{C}$ ) and the reaction mixture was checked by TLC. The mixture was diluted with water $(50 \mathrm{~mL})$ and then extracted by EtOAc $(100 \mathrm{~mL} \times 3)$. The combined organic phases were washed with water and brine, and dried over anhydrous $\mathrm{MgSO}_{4}$. The crude was purified by column chromatography over silica gel using $n$-hexane:EtOAc (15:1) to obtain $\mathbf{1}$ $(0.43 \mathrm{~g}, 92 \%)$.

\subsection{Microglial Cell Culture and Measurement of Nitric Oxide (NO)}

A murine microglial cell line (BV2) was cultured in Dulbecco's modified Eagle medium (DMEM; Gibco, USA) supplemented with 5\% fetal bovine serum (Hyclone, Logan, UT, USA). The production of NO was determined by measuring the accumulation of nitrite in the culture medium $24 \mathrm{~h}$ after stimulation with LPS $(0.5 \mu \mathrm{g} / \mathrm{mL})$ by the Griess reagent as in our previous report [14].

\subsection{Measurement of NADPH Oxidase Activity}

NADPH oxidase activity was measured as described previously [14]. Test compounds were added to the wells of a bioluminescence plate and incubated with $50 \mu \mathrm{g}$ of cell homogenate for $20 \mathrm{~min}$ at $37{ }^{\circ} \mathrm{C}$ in the dark. $\mathrm{O}_{2}^{-}$production was stimulated with $200 \mu \mathrm{M} \mathrm{NADPH}$, and the chemiluminescence was monitored for $30 \mathrm{~min}$, after which the AUC (area under the curve) was calculated to represent reactive oxygen species production (NADPH activity).

\subsection{Measurement of DPPH Radical Scavenging Capacity}

A DPPH radical scavenging capacity assay was performed as in our previous report [12]. The compound was diluted with $\mathrm{MeOH}$ into a range of concentrations $(0.1-50 \mu \mathrm{M})$. DPPH (Sigma-Aldrich, USA) solution (200 $\mu \mathrm{L}$, final concentration: $200 \mu \mathrm{M}$ in $\mathrm{MeOH}$ ) was added to $10 \mu \mathrm{L}$ of each diluted sample in a 96-well microplate, and the resulting solution was allowed to react for $30 \mathrm{~min}$ in the dark at ambient temperature. The absorbance caused by the DPPH radical at $517 \mathrm{~nm}$ was determined by a microplate-spectrophotometer. The radical scavenging capacity is expressed as delta $\mathrm{OD}_{517}\left(\Delta \mathrm{OD}_{517}\right)$, and values are the means of three replicates. An antioxidant, Trolox (OXIS, USA), was included as a reference. 


\section{Conclusions}

In summary, a new benzenoid, benzocamphorin F (1), was isolated from the fruiting body of Taiwanofungus camphorates for the first time. The structure of 1 was fully elucidated by 2D-NMR analysis and also by an efficient and simple method for chemical synthesis. This novel method has several advantages over the other methods, such as high yield, fewer reaction steps, faster reaction rate, and easy work-up without producing any significant by-product. The bioactivity examination results indicated that compound $\mathbf{1}$ displayed potent NO-reducing activities in microglial cells and thus it had potential to be an anti-inflammatory drug for the treatment of NO-dependent neurodegenerative disorders.

\section{Acknowledgments}

The authors are grateful for financial support from the National Science Council of Republic of China awarded to Tian-Shung Wu.

\section{Conflict of Interest}

The authors have no conflict of interest to report.

\section{References}

1. Hsieh, Y.H.; Chu, F.H.; Wang, Y.S.; Chien, S.C.; Chang, S.T.; Shaw, J.F.; Chen, C.Y.; Hsiao, W.W.; Kuo, Y.H.; Wang, S.Y. Antrocamphin A, an anti-inflammatory principal from the fruiting body of Taiwanofungus camphoratus, and its mechanisms. J. Agric. Food Chem. 2010, 58, 3153-3158.

2. Chen, J.J.; Lin, W.J.; Liao, C.H.; Shieh, P.C. Anti-inflammatory benzenoids from Antrodia camphorata. J. Nat. Prod. 2007, 70, 989-992.

3. Wu, S.H.; Yu, Z.H.; Dai, Y.C.; Chen, C.T.; Su, C.H.; Chen, L.C.; Hsu, W.C.; Hwang, G.Y. Taiwannofungus, a polypore new genus. Fungal Sci. 2004, 19, 109-116.

4. Tsai, Z.T.; Liaw, S.L. The Use and the Effect of Ganoderma; Sang-Yun Press: Taichung, Taiwan, 1982; p. 116.

5. Chen, C.J.; Su, C.H.; Lan, M.H. Study on solid cultivation and bioactivity of Antrodia camphorata. Fungal Sci. 2001, 16, 65-72.

6. Liu, D.Z.; Liang, H.J.; Chen, C.H.; Su, C.H.; Lee, Z.H.; Huang, C.T.; Hou, W.C.; Lin, S.Y.; Zhong, W.B.; Lin, P.J.; et al. Comparative anti-inflammatory characterization of wild fruiting body, liquid-state fermentation, and solid-state culture of Taiwanofungus camphoratus in microglia and the mechanism of its action. J. Ethnopharmacol. 2007, 113, 45-53.

7. Rao, Y.K.; Fang, S.H.; Tzeng, Y.M. Evaluation of the anti-inflammatory and anti-proliferation tumoral cells activities of Antrodia camphorata, Cordyceps sinensis, and Cinnamomum osmophloeum bark extracts. J. Ethnopharmacol. 2007, 114, 78-85.

8. Wu, S.J.; Leu, Y.L.; Chen, C.H.; Chao, C.H.; Shen, D.Y.; Chan, H.H.; Lee, E.J.; Wu, T.S. Camphoratins A-J, potent cytotoxic and anti-inflammatory triterpenoids from the fruiting body of Taiwanofungus camphoratus. J. Nat. Prod. 2011, 73, 1756-1762. 
9. Shi, L.S.; Chao, C.H.; Shen, D.Y.; Chan, H.H.; Chen, C.H.; Wu, S.J.; Leu, Y.L.; Shen, Y.C.; Kuo, Y.H.; Lee, E.J.; et al. The constituents and biological activities from the fruiting body of Taiwanofungus camphoratus. Bioorg. Med. Chem. 2011, 19, 677-683.

10. Lee, C.L.; Huang, C.H.; Wang, H.C.; Chuang, D.W.; Wu, M.J.; Wang, S.Y.; Hwang, T.L.; Wu, C.C.; Chen, Y.L.; Chang, F.R.; et al. First total synthesis of antrocamphin A and its analogs as anti-inflammatory and anti-platelet aggregation agents. Org. Biomol. Chem. 2011, 9, 70-73.

11. Mao, H.; Fieber, L.A.; Gawley, R.E. Novel modulator of NaV1.1 and NaV1.2 $\mathrm{Na}^{+}$channels in rat neuronal cells. ACS Med. Chem. Lett. 2010, 1, 135-138.

12. Bates, R.W.; Gabel, C.J.; Ji, J.; Thota, R.D. Synthesis of phenolic natural products using palladium catalyzed coupling reactions. Tetrahedron 1995, 51, 8199-8212.

13. Varma, R.S.; Dahiya, R.; Kumar, S. Micro-wave- assisted henry reaction: Solventless synthesis of conjugated nitroalkenes. Tetrahedron Lett. 1997, 38, 5131-5134.

14. Wang, Y.H.; Wang, W.Y.; Chang, C.C.; Liou, K.T.; Sung, Y.J.; Liao, J.F.; Chen, C.F.; Chang, S.; Hou, Y.C.; Chou, Y.C.; et al. Taxifolin ameliorates cerebral ischemia- reperfusion injury in rats through its anti-oxidative effect and modulation of NF-kappa B activation. J. Biomed. Sci. 2006, $13,127-141$.

(C) 2012 by the authors; licensee MDPI, Basel, Switzerland. This article is an open access article distributed under the terms and conditions of the Creative Commons Attribution license (http://creativecommons.org/licenses/by/3.0/). 